\title{
What Are the Core Elements Necessary for Effective Digital Asset and Media Management Practice?
}

\author{
Mengyu Xing \\ The Center for Social Media Research, Peking University, Beijing, China \\ Email: xingmengyu1@outlook.com
}

How to cite this paper: Xing, M. Y. (2021). What Are the Core Elements Necessary for Effective Digital Asset and Media Management Practice?. Open Journal of Social Sciences, 9, 339-350.

https://doi.org/10.4236/jss.2021.910024

Received: September 14, 2021

Accepted: October 26, 2021

Published: October 29, 2021

Copyright (๑) 2021 by author(s) and Scientific Research Publishing Inc. This work is licensed under the Creative Commons Attribution International License (CC BY 4.0).

http://creativecommons.org/licenses/by/4.0/

\section{(c) (i) Open Access}

\begin{abstract}
With the digital assets increase, Digital Asset Management (DAM) has become more crucial than ever before. DAM increases the efficiency of managing contents and helps maximize the value of content. This research through two case studies discovers the core elements necessary for effective DAM practice, including BBC Redux and The World Digital Library. Findings show that in selecting a DAM system, managing metadata and understanding user needs are the most necessary elements for effective DAM practice. In addition, this research highlights that in the process of DAM practice, every element interacts with the others. People still have to look at the DAM from a comprehensive perspective of a DAM ecosystem.
\end{abstract}

\section{Keywords}

Digital Asset Management, DAM System, Metadata, User Needs

\section{Introduction}

With the development of communications technology, digital asset management (DAM) has become more and more necessary and thus always an area of concern. Digital is pervasive and with the popularity of mobile devices people can acquire and create digital assets. In the UK $78 \%$ of adults have a smart phone and 58\% have a tablet (Ofcom, 2018a). With the significant increase of the number and kinds of digital assets, managing these assets becomes a challenge. One study shows that the average person looks for a file 83 times a week during working hours and fails to find it 35 per cent of the time (Goldstein, 2016). DAM not only increases the efficiency of managing content but also helps maximises the value of content. Regli (2016: p. 3) argues "digital asset manage- 
ment as a discipline and a technology is all about the control, flexibility, portability, access, and reporting of digital assets among organisations, customers, partners, and suppliers." Specifically, "a digital asset corresponds to a media file or files that have an intrinsic or acquired value" (Regli, 2016). Simply, a digital asset includes a media file plus its metadata. For example, e-books, email, video and audio all can be considered as digital assets. However, as Thibodeau (2002) indicates, both the variety and complexity of media files are growing. In order to solve the challenge of digital assets, the management of digital assets throughout therefore lifetime is necessary (Regli, 2016; Lipsey, 2010). There are many key elements involved in DAM, such as workflows, business processes, metadata strategy, user needs, and devising a DAM system itself. Based on case studies from both the television broadcasting industry and libraries, the study will analyse and evaluate the core elements necessary for effective digital asset and media management practice. It first looks at the factors in selecting a DAM system, followed by demonstrating the elements of managing metadata, and finally it analyses the factors in understanding user needs.

\section{Core Elements for Effective DAM Practice}

The core elements necessary for effective DAM practice are a widely discussed topic. In fact, indications can be found in one of the definitions of DAM. Regli (Regli, 2016) argues that "DAM is concerned with delivering the right content to the right people, on all devices mostly in real time." This emphasis includes three key questions: how to deliver the right content? How to find the right content? Who are the right people? This emphasis primarily considers a DAM system as a delivery carrier; metadata leads people to find the right content; the right people can be defined as people who need the content. Therefore, it can be firstly predicted that the core elements are selecting an appropriate system of storing and archiving the digital assets, of managing metadata relevant to that process, as well as understanding the needs of users based also in part of their interaction with metadata. This essay will use case studies to explain in more detail why these elements are necessary. Considering that different industries have different functions and purposes and uses of digital assets, this essay will choose two of the representative industries, including the library field and the television broadcasting field.

\subsection{Selecting an Appropriate System}

\subsubsection{The Importance of DAM Systems}

Selecting an appropriate DAM system is a primary element for DAM, which includes software and hardware. Regli (2016) states, "DAM systems represent the related components that work together to facilitate the lifecycle of assets." The system architecture can build a relationship with and between these components. The capabilities of DAM systems include various activities throughout the lifecycle of digital assets. For instance, Real Story Group has isolated a set of core characteristics of DAMM systems, including "ingest, secure, store, transform, 
relate, process, find, preview and produce/publish" (Regli, 2016). The above characteristics of DAM systems all play important roles in managing digital assets. In the following paragraphs, this essay wills specifically analyse the case of the $\mathrm{BBC}$ in to discuss these in more detail.

\subsubsection{Case Study: BBC Redux}

There are many challenges for managing digital assets concerning different industries. DAM systems organise the fundamental elements relevant to the use of digital assets to deal with the challenges facing an organisation. The BBC Redux is a great example. Specifically, the primary challenge for the BBC is storage. The digital assets of this field are more likely to exist in audio and video, which require vast storage space. For example, Regli (Regli, 2016) indicates that high definition files require significant storage and processing to convert. Redux has a good capability of storage. This system contains over 3 million TV and radio programmes (DotEcon, 2018). It also can adopt IMF methodologies; according to statistics, "about $25 \%$ of storage space can be freed by adopting it" (ibid). In addition, Redux increases accessibility to digital assets. Before using Redux, the archive existed in physical tapes that had to be requested from facilities and physically delivered to staff (BBC, 2018a). Additionally, searching is a big challenge. Alton (Alton, 2018) mentions that it would take decades for one person to manually watch all BBC broadcast programming in order to index and archive it. Redux significantly increases the findability of assets. For example, the system can search words/phrases in a programme and allows users to make short clips (DotEcon, 2018). In addition, interoperability also is a challenge. The BBC commission content from a wide range of producers across the UK and beyond. In this system, assets can be transformed into different formats to deliver to other systems. BBC staff can access the archive via a basic system API (ibid). Redux also can enforce security through access control for different types of employees at the BBC. It also offers encryption to protect the intellectual property of digital assets. However, it is also user friendly, as one can just register for Mobile Apps on a personal device (BBC, 2019a). Additionally, scalability is an important advantage for Redux. Redux can be combined with other systems. Researchers designed another advanced system called "Snippets" to support the Redux work (BBC, 2019b). Particularly, Redux not only supports current needs but also supports future needs. From the case of Redux, we can find that a good DAM system has the ability to help people managing their assets effectively.

An appropriate DAM system not only helps enterprises deal with challenges but also helps enterprises achieve their goals. Reducing costs, generating new revenue streams and enhancing market or brand perception typically can be considered as three goals for many companies. A DAM system can help enterprises to achieve these goals. However, developing a DAM system is expensive. However, DAM systems can significantly save costs, once installed. DAM can save the company at least $20 \%-30 \%$ of cost of working (Marino, 2018). It also 
has a high return on investment. According to statistics supplied by DotEcon (DotEcon, 2018), Redux and Snippets can together obtain benefits estimated at least $£ 53.2$ million, while they only spend $£ 1.39$ million for R\&D and purchase of the DAM systems. People can see more detail in Table 1. In addition, Redux saves significant research time, requesting time, and in transcoding archive contents (BBC, 2018a). Therefore, it also can contribute the enhancing brand perception, because the system has increased the number of archive materials that producers use in their content, improving the quality of programming (ibid).

\subsubsection{The Special Meaning of "Appropriate"}

Enterprises need to choose an "appropriate" DAM system to meet their needs rather than paying attention to achieving a perfect DAM system. There are five deployment model options available, including on-premise, private cloud, public cloud, SaaS and Hybrid. Different models have different features (Regli, 2016). Organisations can choose one model according to the following points. Firstly, the organisational requirements are the primary factor that needs to be considered. Specifically, Regli (Regli, 2016) highlights that the key question for an enterprise is "How can the system's features help or hinder organisations in achieving their requirements?" In addition, enterprises need to be in accord with the capital budget and achieve a return on investment (ROI). Many DAM vendors in the marketing are providing an ROI calculator, as a persuasive way to attract customers. Regli (Regli, 2016) and Kaplan (Kaplan, 2009) all indicate that buying a DAM system includes various fees; the bigger the scale bigger, the higher the fee. For example, for small-scale organisations, the basic capabilities of a DAM system could meet their needs. They can choose a cloud or full-scale SaaS model, which does not involve hardware costs (Regli, 2016). However, a good DAM system not only needs to meet the current needs but also future needs. An "appropriate" system must combine different aspects.

\subsubsection{The Relation between DAM Systems and Other Elements}

Some elements are more important in the selection of DAM systems. There are many elements crucial to DAM. Regli (Regli, 2016) emphasises that "effective implementation of DAM also needs to make a connection with other elements". However, there is no doubt that DAM systems are a technology infrastructure. Without DAM systems, other elements will not be possible to carry out successfully. The British Library (The British Library, 2017) indicates that technological obsolescence is the greatest barrier for the preservation of digital assets. Delaney and Jong (Delaney \& Jong, 2015) argue that technology can be always considered as a driver for digital assets, as content cannot be accessed without the use of machinery, hardware and software. For example, the BBC undertook a project called the Domesday project, which collected lots of text and video from the public (Saulles, 2015). However, after 15 years, it is almost impossible to find hardware to read the various formats used (ibid). From this example, we can identify that without the support of sustainable DAM systems, digital assets cannot maintain a long-time lifecycle. 
Table 1. Benefits summary of Redux and Snippets, source from DotEcon (2018).

\begin{tabular}{|c|c|c|}
\hline \multicolumn{3}{|c|}{ Benefits Summary of the Redux and Snippets Systems } \\
\hline & Lower bound & Upper bound \\
\hline \multirow{3}{*}{ Direct financial benefits } & $\begin{array}{l}\text { - } £ 32 \text { million in cost savings associated with } \\
\text { staff time (Redux only 2009-2016) }\end{array}$ & $\begin{array}{l}\text { - } £ 32 \text { million in cost savings associated with staff time } \\
\text { - (Redux only 2009-2016) }\end{array}$ \\
\hline & $\begin{array}{l}\text { - } £ 11 \text { million in cost savings associated with } \\
\text { staff time (Snippets 2011-2016) }\end{array}$ & $\begin{array}{l}\text { - } £ 11 \text { million in cost savings associated with staff time } \\
\text { (Snippets 2011-2016) }\end{array}$ \\
\hline & $\begin{array}{l}\text { - } £ 165,000 \text { in cost savings associated with } \\
\text { reduced shipping of physical media }\end{array}$ & $\begin{array}{l}\text { - } £ 660,000 \text { in cost savings associated with reduced shipping } \\
\text { of physical media }\end{array}$ \\
\hline $\begin{array}{l}\text { Benefits to users from new } \\
\text { services or improved quality }\end{array}$ & \multicolumn{2}{|c|}{$£ 10$ - 15 million to date in terms of benefits to Redux/Snippets users. } \\
\hline Total benefits estimate & $£ 53.2$ million & $£ 58.7$ million \\
\hline Estimate of costs attributable to & \multicolumn{2}{|l|}{$£ 1.39$ million } \\
\hline BBC R\&D to date & \multicolumn{2}{|c|}{ (around $£ 432,400$ of human expenditure and $£ 960,000$ of R\&D expenditure) } \\
\hline
\end{tabular}

In addition, an appropriate DAM system can support other elements to ensure the maximum value of digital assets. For example, workflows are structured processes around rich media assets, which includes semi-automated and automated processes that are enabled by the DAM. In addition, discovering the value of digital assets can be restricted by DAM systems. For example, the British Library highlights that the ability of collection of metadata to support service transformation has been restricted by an over-complex systems infrastructure. Especially, it must highlight those technology innovations have a strong influence on the DAM. The BBC has been developing artificial intelligence (AI) in their practice. In 2018, BBC Four produce an hour of programming, picked from the BBC's archive entirely automatically, using machine learning techniques (Cowlishaw, 2018). This is why highlight technology is one of the most important elements in effective digital asset management. Both Regli (2016: p. 44) and Marino (2018: p. 12) mention that there is another element which is as important as the DAM system you choose. This element is managing metadata.

\subsection{Managing Metadata}

\subsubsection{The Key Role of Managing Metadata in DAM Practice}

Managing metadata is the heart of effective DAM. More recently, Marino (Marino, 2018) highlights that "metadata is the driving force behind virtually all DAM-related functions." Both Regli (Regli, 2016), and Gilliland (Gilliland, 2016) all discuss the critical roles of metadata in the DAM. Specifically, NISO (NISO, 2004) defines that "metadata is structured information that describes, explains, locates, or otherwise makes it easier to retrieve, use, or manage an information resource". Simply, metadata is data about data. Regli (Regli, 2016) highlights that in order to realise the value of digital content, an organisation must produce metadata. Gilliland (Gilliland, 2016) explains that "all media files have three features: content, context, and structure, all of which can be and should be reflected through metadata." In different industries, organisations increasingly pay 
more attention to the management of metadata. For example, in 2013, the British Library published their first metadata strategy with the theme of "Unlocking the Value". This year, the British Library launched a second metadata strategy, called "Foundations for the Future". From their titles, we can identify the increased importance of managing metadata. Specifically, Gilliland (Gilliland, 2016) categorizes metadata by function into administrative, descriptive, preservation, use and technical metadata. Different types of metadata all play important roles in DAM.

\subsubsection{Case Study: The World Digital Library}

Managing metadata is complex in actual situations. This essay will use the case of the World Digital Library (WDL) to demonstrate more detail about managing metadata. WDL is a collaboration of the Library of Congress (2018) with numerous other national institutions. According to WDL (2019a) statistics, the project brings together 1,057,175 items in about 145 languages in 193 countries. The consistency and interoperability of metadata is a primary challenge in WDL. Eklund and Wray (Eklund \& Wray, 2010) reveal that the inconsistency of metadata can seriously affect the quality of results in search queries. However, it is difficult to collect consistent metadata for WDL. These assets were collected by approximately 200 institutions from 81 countries, each institution uses a different way to collect metadata (WDL, 2019a). In addition, WDL includes 8 types of items with different forms. This means it requires different kinds of metadata. Metadata standards are a useful way to solve this challenge. Gilliland (Gilliland, 2016) and Joint (Joint, 2009) agree that standards can facilitate consistency and interoperability. Boughida (Boughida, 2005) classifies metadata standards into "data structure standards, data value standards, data content standards, and data format/technical exchange standards." WDL (WDL, 2019b) choose MARC, Dublin Core, MODS, TEI and UniMARC as data structure standards, which focus on the categories and organisation of metadata elements to form a framework for preserving relationships and hierarchies between elements (Boughida, 2005). At the same time, WDL also applied a series of data value standards, which "are the terms, names, and other values that are used to populate data structure standards or metadata element sets, including controlled vocabularies, thesauri, controlled lists" (Gilliland, 2016). Svenonious (Svenonious, 1986) highlights that control vocabulary can solve the retrieval problem caused by the use of natural language in the search. For example, WDL follows the "Virtual International Authority File" to control the people names and corporate names; follows the Dewey Decimal Classification system to control topic words (WDL, 2019b). WDL also provides detailed instructions to support partners to use these. While these standards have greatly reduced part of the complexity of metadata, there are still other challenges.

The second challenge is the multiliguality of metadata. The WDL is available free of charge and in seven multilingual formats. Diekema (Diekema, 2012) indicates that managing metadata is one of the challenges in digital libraries in- 
dustries and has certain aspects that complicate matters for a multilingual digital library. Karvounarakis and Kapidakis (Karvounarakis \& Kapidakis, 2000) and Bia et al. (Bia et al., 2005) all highlight that it is difficult to translate metadata into different languages and still make sense to users. WDL organised a translation and language committee and established some principles before translating languages. This process is expensive and time-consuming (WDL, 2019b). Both Michener (Michener, 2006), Minor et al. (Minor et al., 2014), Pryor (Pryor, 2007) and Gilliland (Gilliland, 2016) all indicate that managing metadata is cost-consuming and time-consuming. So, in this case, funding can be considered as the third challenge. In addition, WDL also carries out other activities. For example, WDL makes several taxonomies. Especially, in order to retrieve one of the ways is that they made interactive maps to display different categories base on different countries. In summary, from this case, we can identify that the management of metadata significantly improves the effectiveness of DAM.

\subsubsection{The Relation between Managing Metadata and Other Elements}

Although there are many core elements in DAM, managing metadata is one of the most necessary elements. The concept of a lifecycle model can help explain the reason. In order to manage digital assets more effectively, Higgins (Higgins, 2008) propose the DCC lifecycle model, then Constantopoulos et al. (Constantopoulos et al., 2009) develop it to the DCC\&U lifecycle model, which both offer "a graphical high-level overview of the lifecycle stages required for successful curation". Managing metadata plays a crucial role throughout each action of the DCC\&U model. For example, the action of "description and representation information" focuses on describing different kinds of metadata (Higgins, 2008). Similarly, the action of "preservation action" also needs to consider the metadata issue, such as assigning preservation metadata (Higgins, 2008). Managing metadata also can influence the usability of the DAM system. Regli (Regli, 2016) highlights that DAM systems do not magically make all your assets searchable without solid metadata planning and governance up front. As mentioned before, choosing systems are important, however, one big challenge is technology configuration change. The preservation of metadata can help people deal with the changes (Kaplan, 2009). Although managing metadata is only one part of the DAM elements, without its users cannot find digital content.

\subsection{Understanding User Needs}

\subsubsection{The Necessity of Understanding User Needs in DAM Practice}

User needs can be seen to drive some DAM systems. User needs also can be called user requirements, to "describe what the user does with the system, such as what activities that users must be able to perform" (Kavanagh, 2019). Markus and Keil (Markus \& Keil, 1994) highlight that a "system does not improve organizational performance or create business value; users and their managers do." To a large extent, the user's needs can influence the workflows and business processes. The British Library (The British Library, 2015) indicates that it "puts 
users at the heart of everything stuff do". Similarly, the BBC (BBC, 2018b) highlights that the most important thing is understanding what user needs are. Users are people who "actively use or operate the system or digital resource." Users are of many different types, firstly internal users and external users; users also can be divided into different types and different levels. Different users have different needs and use different workflows.

\subsubsection{Understanding User Needs in DAM Practice}

Considering user needs should be the priority of managing assets in DAM practice.

Specifically, the foundational user need is usability, which is "a quality attribute that assesses how easy user interfaces are to use" (Nielsen, 2012). Simply, this is to assess how effective is it for users to use digital assets. However, managers need to discover more specific user requirement to help users reduce risk and solve problems. For example, intellectual property rights issues have always been seen as a challenge for enterprises. There are lots of news reporting it, such as a woman suing Chipotle for 2.2 billion dollars for using a photo of her without consent (DL CARE, 2017). Even more recently, because of unlawful use of music from a Batman film, American president Trump has had a promotional video removed from Twitter (BBC, 2019c). DAM can meet the needs of users to solve this problem. Organisations can choose a system with the function of tracking IP. According to a survey, DAM can help companies avoid hundreds of thousands of dollars in copyright infringement claims (Marino, 2018). Managing digital assets based on user needs will greatly improve the effectiveness of users and reduce risk.

Considering the needs of external users also is very important, which can contribute to the development of business. In considering the $\mathrm{BBC}$, the operating landscape of the television and broadcasting industries has changed rapidly. Especially, consumption habits are changing at a significant pace for young people. For example, now BBC brand awareness amongst youngsters is lower than YouTube and Netflix (Ofcom, 2018b). Due to the new forms of music streaming, listening to live radio among young adults is decreasing by about $20 \%$ (Ofcom, 2018c). Music streaming has grown by $40 \%$ in a year (ibid). The numbers of adults who have smart speakers has doubled. In order to deal with this situation, the $\mathrm{BBC}$ plan to improve their services and platforms. This requires the managing of assets also need to change and update in order to support their business strategy. For example, personalisation is an increasingly creative way to attract users through a DAM system. The BBC iPlayer uses machine learning to provide personalised recommendations to users based on their viewing habits (BBC, 2018c). Additionally, Goodrum (Goodrum, 2005) mentions that users can create their own textual descriptors using tags. Summarily, enterprises need a DAM system to know what they need ranging from basic work to reduce risk to facing competition.

In real situations, ignoring the user's needs can lead to many negative impacts 
on the DAM. Sometimes, systems designers focus on the technical challenges of expert system engines, rather on the organisational problems of motivating users. Marcus and Keil provide a case that illustrates the importance of user needs. CONFIG is an expert system, which aims to assist sales reps representatives to produce error-free product configurations before quoting prices at the company CompuSys (Markus \& Keil, 1994). The system produces high-quality configurations and is intended to reduce costly allowance, but the sales reps didn't use it. Then the company undertook a redeployment project to make the system more user-friendly. However, the sales reps still hardly used the system. The main reasons are that sales reps were not motivated to use it and had a disincentive to use it (ibid). There are several ways to help manager understand their users, data analytics, interviews, focus groups, surveys, usability testing. Summarily, there is a strong link between use needs and the successful DAM practice.

\subsubsection{The Relation between Understanding Users Needs and Other Elements}

Use needs are a priority in DAM practice. One reason can be found in the DAM maturity model. Regli (Regli, 2016) discusses the maturity model as a methodology, which uses 15 dimensions organised into four categories to evaluate the effectiveness of DAM. There are five levels in each evaluation of dimension, including Ad Hoc, Incipient, Formative, Operational and Optimal. It is interesting to mention that according to the different level's marking criteria, we can identify that the highest level of each dimension almost pays more attention for user needs. For example, talking about governance, which can ensure that "the DAM strategy and policies are actually implemented, and the required processes are correctly followed" (Regli, 2016). From level's marking criteria, we can identify one of the differences between the operational level and optimal level is "utilization of end-user feedback". Specifically, feedback from users can make governance teams understand what exactly a user needs, which can promote better governance to increase the effectiveness of DAM. McGraw (McGraw, 2014) agrees that establishing proper governance for DAM must consider superior user experience and adherence to the user's culture. As a result, from this aspect, we can consider the user's need is a necessary element to improve the effectiveness of the DAM.

\section{Critical Analysis}

The success of DAM implementation is made up of many elements. As this essay has demonstrated when we discuss one element, it is impossible to avoid relating it to other elements. In other words, DAM practice is a big picture and every element in the DAM ecosystem mutually interacted. Just rely on the elements discussed above is not enough to deal with the complexity of DAM. Stakeholders need to think about DAM from an entire DAM ecosystem. However, it is still necessary to consider which elements are more necessary than others, because there are further elements that should be factored into DAM solutions, such as 
an adequate budget. But one thing we need to consider, we live in an ever-changing world, not just of technology updates but also changes in stakeholder requirements. People need to constantly adapt to change and innovate. Innovation is thus another important aspect of DAM practice, especially technological innovation but not for its own sake but, again, to be prioritised in terms of all types of users' needs. How technology has an agency, in other words determining use, for example, rather than neutrally meeting user needs, is a controversial topic. But technology more and more becomes a power to change or even to shape activities in DAM. For instance, AI is already applied in DAM systems and can unlock unforeseen functions of DAM.

\section{Conclusion}

In conclusion, selecting a DAM system, managing metadata and understanding user needs are the most necessary elements for effective DAM practice. The above three elements indeed are the most important elements for effective DAM practices. But in the process of DAM practice, every element interacts with the others. People still have to look at the DAM from a comprehensive perspective of a DAM ecosystem. Further research could conduct research more specific focus on the relation among the elements mentioned before.

\section{Funding}

This research did not receive any specific grant from funding agencies in the public, commercial, or not-for-profit sectors.

\section{Conflicts of Interest}

The author declares no conflicts of interest regarding the publication of this paper.

\section{References}

Alton, C. (2018). AI and the Archive-The Making of Made by Machine.

https://www.bbc.co.uk/rd/blog/2018-09-artificial-intelligence-archive-made-machine

BBC (2018a). Review of the BBC's Research \& Development Activity.

http://downloads.bbc.co.uk/aboutthebbc/insidethebbc/reports/pdf/rdreview.pdf

BBC (2018b). Annual Report and Accounts 2017/2018.

http://downloads.bbc.co.uk/aboutthebbc/insidethebbc/reports/pdf/bbc annualreport 2 01718.pdf

BBC (2018c). Artificial Intelligence and Machine Learning at the BBC: From the iPlayer to...Infinity?

https://www.bbc.co.uk/blogs/aboutthebbc/entries/84a7deb0-4280-4cc8-af81-0b1b14e5c $\underline{994}$

BBC (2019a). BBC Archive Services. https://archiveservices.tools.bbc.co.uk/faq

BBC (2019b). Snippets. https://www.bbc.co.uk/rd/projects/snippets

BBC (2019c). Trump's Video Tweet Using Batman Music Removed Due to Copyright. https://www.bbc.co.uk/news/world-us-canada-47878038 
BBC (2019d). BBC Archive Services. https://archiveservices.tools.bbc.co.uk/faq

Bia, A., Malonda, J., \& Gómez, J. (2005). Automating Multilingual Metadata Vocabularies. International Conference on Dublin Core and Metadata Applications, Madrid, 12-15 September 2005, 201-208.

Boughida, K. (2005). CDWA Lite for Cataloguing Cultural Objects (CCO): A New XML Schema for the Cultural Heritage Community. Humanities, Computers and Cultural Heritage: Proceedings of the XVI International Conference of the Association for History and Computing, Amsterdam, 14-17 September 2005, 49-56.

Constantopoulos, P., Dallas, C., Androutsopoulos, I., Angelis, S., Deligiannakis, A., Gavrilis, D., \& Papatheodorou, C. (2009). DCC\&U: An Extended Digital Curation Lifecycle Model. International Journal of Digital Curation, 4, 34-45. https://doi.org/10.2218/ijdc.v4i1.76

Cowlishaw, T. (2018). Using Artificial Intelligence to Search the Archive. https://www.bbc.co.uk/rd/blog/2018-10-artificial-intelligence-archive-television-bbc4

Delaney, B., \& de Jong, A. (2015). Media Archives and Digital Preservation: Overcoming Cultural Barriers. New Review of Information Networking, 20, 73-89. https://doi.org/10.1080/13614576.2015.1112626

Diekema, A. R. (2012). Multilinguality in the Digital Library: A Review. The Electronic Library, 30, 165-181. https://doi.org/10.1108/02640471211221313

DL CARE (2017). Woman Sues Chipotle for \$2 Billion for Using a Photo of Her without Consent. https://petapixel.com/2017/01/06/woman-sues-chipotle-2-billion-using-photo-without -consent

DotEcon (2018). Analysis of Research and Development Investment: A Report for BBC $R \& D$. http://www.dotecon.com/assets/images/DotEconRD.compressed.pdf

Eklund, P. W., \& Wray, T. (2010). Social Tagging for Digital Libraries Using Formal Concept Analysis. Proceedings of the 7th International Conference on Concept Lattices \& Their Applications, Sevilla, 19-21 October 2010, 139-150. https://doi.org/10.1109/RIVF.2010.5633402

Gilliland, A. (2016). Setting the Stage (3rd ed.). Getty Publications.

Goldstein, B. (2016). Digital Asset Management Is Not Software or a System, But How to Do Business. Journal of Digital Media Management, 5, 6-11.

Goodrum, A. A. (2005). I Can't Tell You What I Want, But I'll Know It When I See It: Terminological Disconnects in Digital Image Reference. Reference \& User Services Quarterly, 45, 46-53.

Higgins, S. (2008). The DCC Curation Lifecycle Model. International Journal of Digital Curation, 3, 453. https://doi.org/10.1145/1378889.1378998

Joint, N. (2009). Practical Digital Asset Management and the University Library. Library Review, 58, 89-96. https://doi.org/10.1108/00242530910936907

Kaplan, D. (2009). Choosing a Digital Asset Management System That's Right for You. Journal of Archival Organization, 7, 33-40. https://doi.org/10.1080/15332740902897360

Karvounarakis, G., \& Kapidakis, S. (2000). Submission and Repository Management of Digital Libraries, Using WWW. Computer Networks, 34, 861-872. https://doi.org/10.1016/S1389-1286(00)00157-2

Kavanagh, B. (2019). Requirements into Functions [Lecture to Digital Asset and Media Management Student]. King's College London.

Library of Congress (2018). Metadata Object Description Schema. 
http://www.loc.gov/marc

Lipsey, D. (2010). What Is DAM-The Discipline and Practice of Digital Asset Management. http://hstalks.com/main/browse talk info.php?talk id=1857\&c=250

Marino, J. (2018). Digital Asset Management: Big Content in a Challenging Landscape. https://doi.org/10.2139/ssrn.3247252

Markus, M. L., \& Keil, M. (1994). If We Build It, They Will Come: Designing Information Systems That People Want to Use. MIT Sloan Management Review, 35, 11.

McGraw, D. (2014). Governance for Digital Asset Management. Journal of Digital Media Management, 2, 203-205.

Michener, W. K. (2006). Meta-Information Concepts for Ecological Data Management. Ecological Informatics, 1, 3-7. https://doi.org/10.1016/j.ecoinf.2005.08.004

Minor, D., Critchlow, M., Hutt, A., Fleming, D., Bergstrom, M. L., \& Sutton, D. (2014). Research Data Curation Pilots: Lessons Learned. International Journal of Digital Curation, 9, 220-230. https://doi.org/10.2218/ijdc.v9i1.313

Nielsen, J. (2012). Usability 101: A Gentle Introduction to the Important Topic of Usability. https://www.nngroup.com/articles/usability-101-introduction-to-usability

NISO National Information Standards Organization (US) (2004). Understanding Metadata. NISO Press.

Ofcom (2018a). Communications Market Report.

https://www.ofcom.org.uk/research-and-data/multi-sector-research/cmr/cmr-2018/int eractive

Ofcom (2018b). Ofcom's Annual Report on the BBC. https://www.ofcom.org.uk/ data/assets/pdf file/0015/124422/BBC-annual-report.pdf

Ofcom (2018c). Public Service Broadcasting in the Digital Age. https://www.ofcom.org.uk/ data/assets/pdf file/0026/111896/Public-service-broadcas ting-in-the-digital-age.pdf

Pryor, G. (2007). Project Store: Making the Connections for Research. OCLC Systems \& Services, 23, 70-78. https://doi.org/10.1108/10650750710720775

Regli, T. (2016). Digital and Marketing Asset Management: The Real Story about DAM Technology and Practices (Vol. 1). Rosenfeld Media.

Saulles De, M. (2015). Information 2.0: New Models of Information Production, Distribution and Consumption. Facet Publishing.

Svenonious, E. (1986). Unanswered Questions in the Design of Controlled Vocabularies. Journal of the American Society of Information Science, 37, 331-340.

https://doi.org/10.1002/asi.4630370509

The British Library (2015). The British Library Collection Metadata Strategy 2015-2018. http://www.bl.uk/bibliographic/pdfs/british-library-collection-metadata-strategy-20152018.pdf

The British Library (2017). Digital Preservation Strategy. https://www.bl.uk/britishlibrary/ /media/bl/global/digital\%20preservation/bl digitalpr eservationstrategy 2017-2020.pdf

Thibodeau, K. (2002). Overview of Technological Approaches to Digital Preservation and Challenges in Coming Years. In: The State of Digital Preservation: An International Perspective, Washington DC, 24-25 April 2002, 4-31.

WDL World Digital Library (2019a). Collection Statistics. https://www.wdl.org/en/statistics

WDL World Digital Library (2019b). Content Preparation. https://project.wdl.org/content 